\title{
Application of Computer Technology in Office Automation
}

\author{
Wu Wei \\ College of Electronics and Information, Hubei Three Gorges Polytechnic, Yichang Hubei, 443000, China
}

Keywords: office automation, computer technology, application

\begin{abstract}
The application of computer technology in the field of office has brought a revolutionary change to people's working mode, which not only greatly improves work efficiency and saves office cost, but also plays a very important role in strengthening the communication and information exchange between internal and external departments. This paper explores the characteristics, current situation of office automation and the significance of applying computer technology, and discusses the application of computer technology in office automation in detail, which is conducive to the improvement of the application level of computer technology in office automation. The definition of office automation has not been unified yet. It is generally believed that modern working mode that is closely connected with advanced science and technology such as computer technology and information technology in office work is office automation. This new working mode is a reform in the field of office, which not only changes the traditional working environment, but also greatly improves the work efficiency and reduces the work cost. As the wide application of computer technology greatly improves the capability of information processing, it plays a key role in the collection and analysis of information as well as the utilization and transmission of information. This is beneficial to strengthen the connection and coordination of all links within the enterprise, effectively enhancing the ability of employees to coordinate their work, and is conducive to the optimization of the enterprise management system.
\end{abstract}

\section{Development of office automation}

\subsection{Characteristics of office automation}

Computer technology is the key to modern office automation. The characteristics of office automation are mainly shown in five aspects. One is equipment. Office automation is closely related to computer equipment, which mainly include two parts, that is, hardware equipment and software equipment. Hardware equipment such as computer, printer and various application software such as financial software, management software and database system give more comprehensive technical support to office automation. The second is efficiency. With the application of computer technology in office automation, the ability of information processing is greatly enhanced, which not only improves the accuracy of information analysis but also shortens the time of information collection, processing and transmission, thus greatly improving the efficiency of work. The third is security. Computer technology closely connects offices, staff and information resources, and builds a more secure and reliable information system based on this. Information sharing is realized through network system, which is more secure and more efficient. The fourth is convenience. Relying on computer technology, office automation makes modern office more convenient and fast. As information resources are shared more conveniently, office efficiency is greatly improved. The fifth is intelligence. Modern office automation has a lot of work that needs to use the intelligent model for office. Through the establishment of open mode of human and computer technology system, people can independently handle various business through this system, which not only improves the work efficiency but also greatly reduces the work cost, as well as can bring good social benefits and economic benefits to enterprises.

\subsection{Current situation of office automation}

Office automation is closely related to computer technology, which can be said to be the product 
as the development of computer technology to a certain extent. Application of computer technology makes office realize automation. In the actual work, the staffs use the computer equipment to collect, analyze, process, transmit, store and maintain various information, so as to conduct systematic management. The tedious office documents and numerous files can be systematically and uniformly managed by computer equipment and network, which greatly improves the traditional working environment and greatly enhances the accuracy and effectiveness of the work. From the current situation of office in China, office automation has been widely used, and the degree of automation has achieved a very great development; the intellectualized office mode has gradually been realized throughout the country, which means that people and equipment system can perform the interaction in open mode. This will greatly save the work cost, making office automation present a diversification trend. Computer technology is the foundation and key to the realization of office automation. With the development of computer technology, the degree of office automation is also constantly improving. It can be said that the standard of modern office is the application of computer technology.

From the application of computer technology in office automation, office automation mainly uses data processing technology in computer technology, and the main software includes Word, Excel, PowerPoint, etc. The office software application greatly improves the accuracy and efficiency of office, and makes the complicated or impossible work become simple, convenient and quick, especially the application of multimedia technology in office, such as image, voice processing. In addition, network technology is used for video conference, and scientific analysis and processing of relevant information of the conference is conducted through computer technology, so as to obtain more reliable judgment and feasibility. Video conference greatly reduces the cost and time of the conference and plays a very important role in improving the work efficiency.

\section{Specific application of computer technology in office automation}

\subsection{Application of information processing technology}

Information processing technology is very important in the daily office, mainly including two aspects, that is, word processing and data processing. The application of this technology in office greatly improves the work efficiency.

\subsubsection{Application of word processing technology in office automation}

In actual office activities, a considerable part of the workload is written work. The application of word processing technology in office activities has completely changed the traditional working mode of handwriting. The use of computer word processing software to input, edit and store texts, etc. plays an extremely important role in improving the efficiency of text editing, and also has the remarkable characteristic, namely convenient writing and storage. Word editing is the basic work of modern automatic office work. Using computer to process words has become the mainstream and advanced working mode of the times, and is an important standard of office automation. Currently, the word processing software used in office mainly include Word that is an office software which people are familiar with, and WPS that is a national Chinese word processing software. The application of these software in office activities not only can satisfy the daily office text input, editing, and modification, but also has typesetting and the experience of a variety of reading model; according to the work, people can use a variety of ways to output the text. In addition, there are also writing templates of various themes. The staff writes the text according to the pattern requirements of the template, which makes the work change easier and more convenient. In text editing, there are also functions such as header and time setting, which makes the text more uniform, greatly simplifying and reducing the work difficulty of the staff, and further improving the work efficiency.

\subsubsection{Application of data processing technology in office automation}

The application of data processing technology in office automation greatly improves the ability and accuracy of data collection, analysis, filing and transmission, and greatly enhances the 
reliability of judgment. It can help enterprises and decision-makers to timely adopt correct strategies, which play a very important role in improving economic benefits. From the current use of the data processing software of in enterprise office, Execl in office software is mainly used. Through the application of this software, it can help the staff to analyze and calculate a large amount of data and can also transform data into graph mode. Through the graph, it shows the change of data, making the change of data clearer, more concise and more straightforward. In addition, the data of different stages can be selected flexibly and analyzed from multiple perspectives according to the actual work, so as to obtain the information required by the enterprise.

\subsection{Application of network technology}

Network technology is the product of combining computer technology and information technology. The application of network technology in the modern office automation establishes a closer relationship between internal departments within the enterprise. At the same time, it strengthens the enterprise's exchanges and communication with the outside world. It can be said that network technology is an inalienable part in office automation. Network technology organically integrates all fields in office automation, and effectively transfers and analyzes all aspects of information data. It can help staff to obtain reliable and feasible information data to the greatest extent, and also quickly share information resources. This plays an important role in improving work efficiency and simplifying work procedure.

As for the application of network technology in office activities, it is mainly used in email and video conference. Enterprises enhance their communication with each other through e-mail and increase the information exchange between each other, which are advantageous to the accuracy and timeliness of information transmission and greatly improve the information processing capacity and efficiency in office activities. In the context of economic globalization, the communication between enterprises is no longer restricted by geographical location. Holding video conference through the network technology not only changes the traditional mode of conference, but also greatly reduces the cost and time for the conference, making enterprises all over the work hold the conference in the shortest time. It greatly strengthens the connection and communication between enterprises, and plays an important role in timely getting access to information and solving the problems. In addition, the contents, data and problems of the conference can be summarized and analyzed by computer, which is conducive to improving staff's ability.

\subsection{Application of multimedia technology}

The application of multimedia technology in the modern office automation has obvious characteristics, mainly reflected in two aspects. One is diversified. Multimedia technology can combine text, image, animation, and sounds in a variety of ways to present them to people. This form makes the audience get more intuitive feelings and immersive experience. It changes the traditional single and boring form of expression, making the explanation more expressive and appealing with the use of the audience's acceptance and understanding. The other is man-machine interaction. The practical application of multimedia technology in office activities improves the degree of automation and greatly enhances work efficiency. For example, in banking, self-service machines provided by banks are often used. Through the use of self-service machines, people can handle a variety of services such as inquiry, deposit, withdrawal and payment, etc. People's use of such self-service machines is the embodiment of man-machine interaction, which not only facilitates customers since they can no longer wait in line, but also reduces staff's workload and effectively improves the efficiency of office. It can be said that multimedia technology application in the field of office changes the traditional mode of work, and greatly enriches the use of multimedia technology to make vivid and interesting report or product display. It can quickly attract the attention of the audience, to facilitate the understanding and impression of the audience, and more easily gain the recognition of the audience. 


\section{Increasing the application of computer technology in office automation}

Improving the level of computer technology in the application of office automation is mainly to strengthen the computer quality of the staff. In the modern office automation activities, in addition to computer equipment and software that can improve the degree of automation, the staff operating the equipment and software is also very important. Because the specific work still needs to be completed by people, it is necessary to improve the overall computer ability of all staffs. Enterprises can carry out computer knowledge education to staff through training, and train them according to the requirements of computer technology in this industry, so that staff can skillfully use the office software required for work. Professional training should be conducted for computer talents who need professional skills and should not be educated with ordinary operators. Education for professional personnel should strengthen the security awareness of computer technology. For example, the security protection of enterprise's computer room takes high-performance firewall and other security software to make the timely search and repair of the vulnerability for enterprise computers, with the establishment of network system to ensure the security of enterprise's computers. The degree of automation application of computer technology in office activities entirely depends on the overall improvement of computer application ability of all staffs. In addition, enterprises should also promote the staffs' ability of autonomous learning for computer application, and strengthen their recognition of the importance of learning computer application. The staffs not only learn how to use the computer, but also should improve ability of training, such as the skilled use of application systems, word processing software, and computer virus prevention and so on. Only when staffs set up the right consciousness of technology and master the computer application ability can the level of the computer technology application in office automation be fundamentally improved.

\section{References}

[1] Zhang Juan. Analysis on the application of computer technology in office automation. Intelligence, 2015 (21).

[2] Zeng Mei'er. Analysis on the application of computer technology in office automation. Major Science and Technology, 2017 (16).

[3] Yang Jie. Analysis on the application of computer information processing technology in office automation. Science and Technology Information, 2016 (14). 